\title{
The unsolved problem of otitis media in indigenous populations: a systematic review of upper respiratory and middle ear microbiology in indigenous children with otitis media
}

\author{
Andrea Coleman ${ }^{1,2^{*}}$ (D), Amanda Wood ${ }^{3}$, Seweryn Bialasiewicz ${ }^{2}$, Robert S. Ware ${ }^{4}$, Robyn L. Marsh ${ }^{5}$ \\ and Anders Cervin ${ }^{1,6}$
}

\begin{abstract}
Background: Otitis media (OM) imposes a great burden of disease in indigenous populations around the world, despite a variety of treatment and prevention programs. Improved understanding of the pathogenesis of OM in indigenous populations is required to advance treatment and reduce prevalence. We conducted a systematic review of the literature exploring the upper airway and middle ear microbiota in relation to OM in indigenous children.

Methods: Papers targeting microbiota in relation to OM in children < 18 years indigenous to Australia, New Zealand, North America, and Greenland were sought. MEDLINE, CINAHL, EMBASE, Cochrane Library, and Informit databases were searched using key words. Two independent reviewers screened titles, abstracts, and then full-text papers against inclusion criteria according to PRISMA guidelines.

Results: Twenty-five papers considering indigenous Australian, Alaskan, and Greenlandic children were included. There were high rates of nasopharyngeal colonization with the three main otopathogens (Haemophilus influenzae, Streptococcus pneumoniae, and Moraxella catarrhalis) in indigenous children with OM. Middle ear samples had lower rates of otopathogen detection, although detection rates increased when molecular methods were used. Pseudomonas aeruginosa and Staphylococcus aureus were commonly detected in middle ear discharge of children with chronic suppurative OM. There was a significant heterogeneity between studies, particularly in microbiological methods, which were largely limited to culture-based detection of the main otopathogens.
\end{abstract}

Conclusions: There are high rates of otopathogen colonization in indigenous children with OM. Chronic suppurative OM appears to be associated with a different microbial profile. Beyond the main otopathogens, the data are limited. Further research is required to explore the entire upper respiratory tract/middle ear microbiota in relation to OM, with the inclusion of healthy indigenous peers as controls.

Keywords: Otitis media, Indigenous, Microbiota, Pediatrics, Systematic review

\footnotetext{
*Correspondence: a.coleman2@uq.edu.au

${ }^{1}$ Faculty of Medicine, The University of Queensland, Brisbane, Queensland, Australia

${ }^{2}$ Queensland Pediatric Infectious Disease Laboratory, Centre for Children's Health Research, Children's Health Queensland Hospital, Queensland University of Technology, Child Health Research Centre, The University of Queensland, 62 Graham Street, South Brisbane, Queensland 4101, Australia Full list of author information is available at the end of the article
}

(c) The Author(s). 2018 Open Access This article is distributed under the terms of the Creative Commons Attribution 4.0 International License (http://creativecommons.org/licenses/by/4.0/), which permits unrestricted use, distribution, and reproduction in any medium, provided you give appropriate credit to the original author(s) and the source, provide a link to the Creative Commons license, and indicate if changes were made. The Creative Commons Public Domain Dedication waiver (http://creativecommons.org/publicdomain/zero/1.0/) applies to the data made available in this article, unless otherwise stated. 


\section{Introduction}

Otitis media (OM) describes a spectrum of pathologies that involve inflammation and/or infection in the middle ear. This spectrum encompasses a continuum from acute to chronic disease that is clinically characterized by fluid in the middle ear [1-4]. OM is highly prevalent in indigenous populations globally, particularly when compared to non-indigenous peers $[5,6]$, and often occurs earlier, more frequently and in more severe forms $[4,5,7]$. Prevalence data reports that up to one third of Greenlandic and Alaskan Inuit, Native American, and Australian Indigenous children suffer from chronic suppurative OM (CSOM) [6, 8-11]. The World Health Organization considers CSOM prevalence of $\geq 4 \%$ indicative of a public health problem serious enough to require urgent attention [12]. OM-related complications result in approximately 21,000 deaths each year worldwide [13]. OM-associated hearing loss can impact significantly on language and social skills development, school attendance and educational outcomes, and downstream effects such as greater contact with the criminal justice system later in life $[4,14,15]$. Medical interventions including liberal antibiotic prescription and vaccination programs have limited effectiveness in indigenous populations [16-18]; thus, new treatment avenues need to be considered.

The reasons for high OM prevalence in indigenous populations are likely to be multi-factorial. Risk factors include poverty, inadequate housing, overcrowding, and exposure to environmental tobacco smoke $[6,8,19,20]$. These risk factors are ubiquitous across indigenous populations worldwide [21]. Genetic susceptibility to OM has not been studied in indigenous populations [22, 23].

We use the term microbiota to refer to the bacterial taxa reported for upper respiratory and middle ear samples, while "microbiome" refers to "the catalog of these microbes and their genes" [24]. The microbiota of the upper respiratory tract (URT) is an important OM risk factor across all populations. Most research to date has focused on the role of the three main otopathogens: Streptococcus pneumoniae, Moraxella catarrhalis, and non-typeable Haemophilus influenzae [25]. It is not currently clear whether commensal bacteria amongst the URT microbiota contribute to, or mitigate, OM risk in indigenous children. In non-indigenous children, $16 \mathrm{~S}$ ribosomal RNA (rRNA) gene analyses have suggested that a "healthy" nasopharyngeal (NP) microbiota is more diverse than that of children with OM [26-29]. This healthy NP microbiota contains bacteria that may be protective or promote microbiota stabilization, including Moraxella, Corynebacterium, Dolosigranulum, Propionibacterium (Cutibacterium), Lactococcus, and Staphylococcus [26-29]. It is currently unknown whether these results are generalizable to indigenous populations.
While high rates of OM are reported for many developing countries, indigenous populations, as defined by the United Nations [30], share unique challenges in relation to OM. Otitis media in indigenous populations is difficult to prevent and treat, therefore we need to gain a better understanding of the microbial pathogenesis to establish knowledge gaps, provide direction for future research, and help guide appropriate prevention and treatment options. The aim of this systematic review is to assess the current knowledge regarding the microbiological etiology of $\mathrm{OM}$ in indigenous children from around the world by examining data pertaining to upper respiratory and middle ear samples.

\section{Methods}

Methods used for this systematic review were developed with reference to the Preferred Reporting Items for Systematic Reviews and Meta-Analyses (PRISMA) statement. The protocol was registered with the International Prospective Register of Systematic Reviews (PROSPERO) (CRD42016033905) prior to commencement.

\section{Inclusion criteria}

All studies exploring the microbiota of the URT (nose, nasopharynx, mouth, oropharynx, throat, tonsils, adenoid, and middle ear) in relation to $\mathrm{OM}$ in indigenous children aged $0-18$ years old were included. For studies that included children without OM and/or did not report microbiology results specifically for children with OM, either only middle ear data were included, or if only the NP was sampled, the studies were excluded. Indigenous populations from Australia, New Zealand, the USA, Canada, and Greenland were included.

\section{Search strategy}

Literature search strategies were developed in collaboration with a health sciences librarian using medical subject headings $(\mathrm{MeSH})$ and key words (Additional file 1). The following electronic databases were searched from inception until 15 August 2017: MEDLINE (from 1946) and CINHAL (from 1982) via EBSCOhost, EMBASE (from 1966), Cochrane Library (from 1996), and Informit (from 1990 to April). To ensure search saturation, we reviewed the reference lists of relevant studies and sought unpublished clinical audits through the Australian Institute of Health and Welfare (https://www.aihw.gov.au/) and The Australian Indigenous Health Info Net (https://healthinfonet.ecu.edu.au/). Two independent reviewers (ACol and AW) revised titles and abstracts, then full-text publications with reference to the inclusion criteria. Study selection inter-rater agreement between the two reviewers was calculated as the proportion of positive agreement (PA) [31]. 


\section{Data extraction}

Two independent reviewers (ACol and AW) extracted data in duplicate onto a Microsoft Excel spreadsheet. Publication authors were contacted where data had been represented graphically or data were missing. We screened for multiple reports from the same study and where multiple reports existed, compared, and extracted relevant data; if inconsistencies existed, we contacted the authors for clarification. The following data were extracted for all studies meeting inclusion criteria: publication year, geographical location, study design, number of participants, age range, ethnicity, number of participants with an OM diagnosis, type of OM, number of controls, anatomical location of sample(s), microbiota investigation method, type and quantity of bacteria, viruses, and fungi detected from each anatomic site. For the purpose of the review, "culture" is defined as culture targeting the three main otopathogens and "extended culture" is defined as culture used to detect bacteria beyond these otopathogens. Only quantitative PCR (qPCR) data were included when both culture and qPCR were used. For longitudinal studies, data relating to both the number of swabs and number of children were extracted, when there were multiple swabs per child. For data obtained from clinical trials, we included data only from samples collected prior to randomization.

\section{Data analysis}

Where there were a sufficient number of studies, meta-analysis of proportions was calculated using random effects analysis via Stata/IC 15; otherwise, we synthesized the data into a systematic narrative. We calculated heterogeneity using $I^{2}$ statistic.

\section{Risk of bias assessment}

Two independent reviewers (ACol and AW) assessed the risk of bias for each study with reference to the Critical Appraisal Skills Program (CASP) Cohort Study Checklist [32]. Within the CASP Checklist, we assessed for the following confounding variables: age, overcrowding, antibiotic use, daycare/school attendance, and concurrent respiratory/upper respiratory tract infection. Study quality was categorized as "poor," "moderate," or "good" based on the CASP Checklist. The overall quality of evidence was judged as high, moderate, low, and very low [33].

\section{Results}

The initial search identified 5592 articles. After screening titles, the abstracts of 956 articles and 332 full-text publications were reviewed (Fig. 1). There was substantial PA between the reviewers of titles $(\mathrm{PA}=0.68)$ and abstracts $(\mathrm{PA}=0.79)$. Twenty-five articles met the inclusion criteria; these were from Australian Indigenous

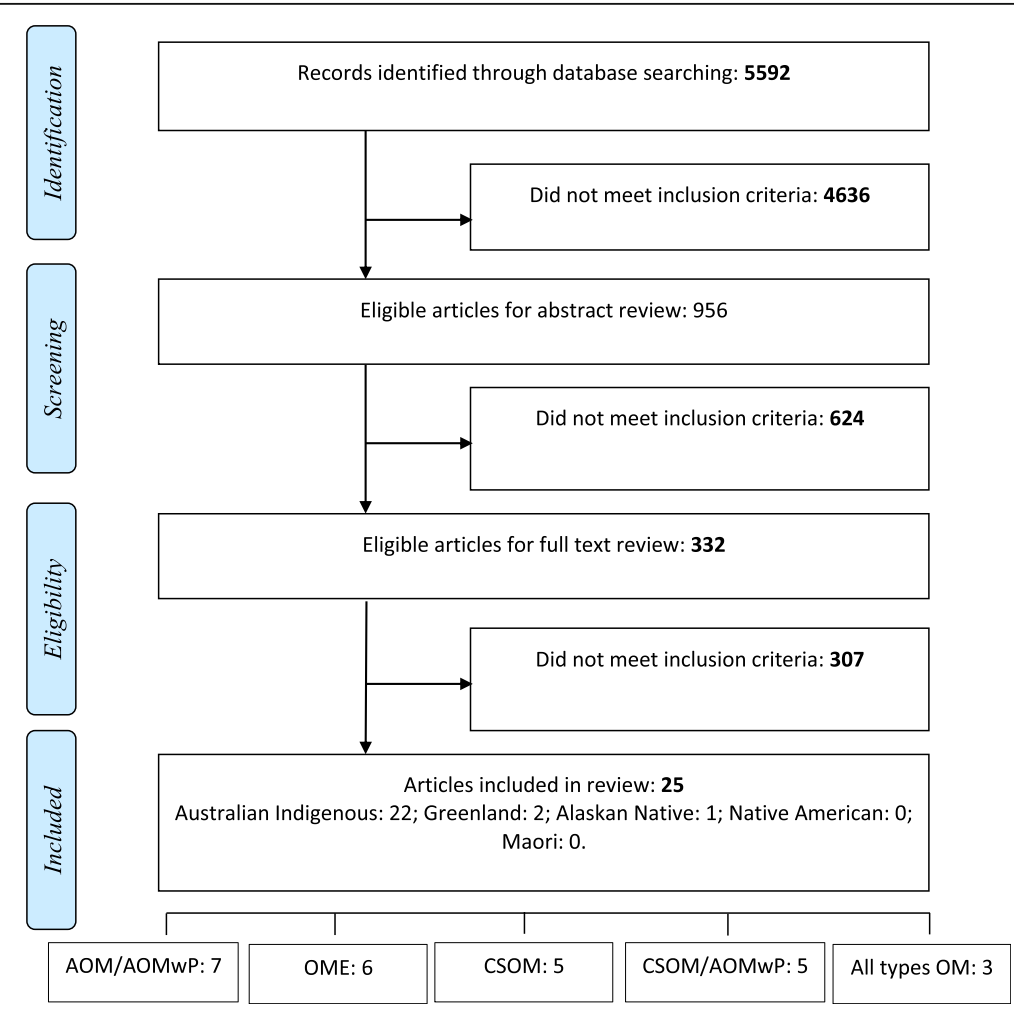

Fig. 1 Literature search and selection. AOM acute otitis media, AOMwP acute otitis media with perforated tympanic membrane, CSOM chronic suppurative otitis media, OME otitis media with effusion 
$(n=22)$, Greenlandic $(n=2)$, and Alaskan Inuit $(n=1)$. No papers reported OM otopathogens or microbiota in Native American or New Zealand Maori children.

\section{Risk of bias assessment}

According to the CASP risk of bias assessment, most studies $(80 \%)$ were judged as either "poor" or "moderate," largely due to confounding variables not being considered (Table 1). Recruitment bias was difficult to assess, as recruitment processes were often poorly documented. Only one study [34] included healthy indigenous controls, and another three $[20,35,36]$ included children without $\mathrm{OM}$ enrolled in longitudinal studies. Within indigenous populations, participants were recruited from limited geographical regions, making generalization beyond these regions difficult. Overall, the quality of the literature was "low."

\section{Heterogeneity}

The literature was limited by methodological and statistical heterogeneity across the studies, including heterogeneity in study design, participant age, OM diagnosis, and laboratory methods (Table 2). Where there were sufficient data to calculate $I^{2}$; most were $>70 \%$, indicating moderate-high heterogeneity (Figs. 2, 3, and 4).

\section{OM clinical definitions and diagnosis}

OM definitions used by the studies are outlined in Additional file 2. Acute $\mathrm{OM}(\mathrm{AOM})$ definitions were consistently based on otoscopy and tympanometry. OM with effusion (OME) was diagnosed based on a type-B tympanogram in 5/ 8 studies; the remaining three studies [37-39] reported data from intra-operative middle ear effusion (MEE) samples, without specifying OME diagnostic criteria. CSOM definitions were heterogeneous and included otorrhoea for > 2 weeks [40, 41], > 6 weeks [42], and broad descriptive terms $[39,43]$. Three studies did not describe specific OM diagnostic criteria [44-46].

\section{Laboratory methods}

Methods used to assess URT and middle ear bacteriology varied across studies (Table 2). Most studies (13/25) used culture conditions specific for detection of the main otopathogens. Nine studies used extended culture to detect a wider range of bacteria. For the culture-based studies, methodological details varied. Most culture-based studies $(13 / 22)$ described the agar plates used and growth conditions [16, 20, 34, 36-40, 42, 43, 47-49]; however, reporting of phenotypic isolate identification tests varied. The remaining studies used non-specific terms or referred to other papers [44-46, 50-55].

Three studies used only molecular methods: two used species-specific qPCR targeting the main otopathogens or
Alloiococcus otitidis [35, 56], and one used $16 \mathrm{~S}$ rRNA gene sequencing [57]. One study used both culture and qPCR [48]. The three studies using qPCR $[35,48,56]$ used the same gene targets for S. pneumoniae and M. catarrhalis. Two studies used the hpd gene to detect $H$. influenzae $[35,56]$ while another used an alternative gene target, $h p d 3$ [48]. Only one paper used qPCR to detect $A$. otitidis [56].

\section{Bacteriology}

\section{Acute otitis media}

AOM bacteriology was reported for Australian and Greenlandic indigenous children, with high prevalence of the three main otopathogens in NP/nose and middle ear specimens across both populations (Fig. 2 and Additional file 3$)$. Co-infection with $>1$ otopathogen was common in the NP, although less frequent in MED (Additional file 3). NP colonization by S. pneumoniae (both populations) or M. catarrhalis (Australian Indigenous) was significantly related to AOM when compared to indigenous peers without $\mathrm{OM}[34,35]$. Beyond the main otopathogens, A. otitidis, Staphylococcus spp., and $\beta$ hemolytic Streptococcus were also detected in the middle ear discharge (MED) of children with AOM with perforated tympanic membrane (AOMwP) (Additional file 4).

\section{Otitis media with effusion}

The one study investigating NP microbiota, and all but one study exploring MEE in children with OME were from Australian Indigenous children. The three main otopathogens were highly prevalent in the NP in children with OME (Fig. 3 and Additional file 3), although only $S$. pneumoniae and $M$. catarrhalis were significantly related to OME in the one study that included a control group [35]. Culture-based studies reported a low prevalence of otopathogens in MEE (Fig. 3, Additional file 3); however, much higher rates were detected in the single study that used molecular methods [57] (Fig. 3). Other bacteria detected in MEE by extended culture included $A$. otitidis, Corynebacterium spp., Pseudomonas aeruginosa, and Staphylococcus aureus (Additional file 4). The single 16S rRNA gene sequencing analysis (Australian Indigenous children) [57] found high rates of the genera Dolosigranulum, Moraxella, Haemophilus, and Streptococcus (Mitis group) in the NP, and Alloiococcus, Haemophilus, and Corynebacterium in MEE (Additional file 5).

\section{Chronic suppurative otitis media}

All but one study investigating CSOM were from Australian Indigenous children. The most commonly reported bacteria from culture-based studies of MED from children with CSOM were $P$. aeruginosa, $S$. aureus, and $H$. influenzae (Fig. 4). P. aeruginosa and $H$. influenzae were often detected in Australian Indigenous children, 
Table 1 Risk of bias assessment

\begin{tabular}{|c|c|c|c|c|c|c|c|c|c|c|c|}
\hline & Reference & $\begin{array}{l}\text { Did the study } \\
\text { address a } \\
\text { clearly } \\
\text { focused } \\
\text { issue? }\end{array}$ & $\begin{array}{l}\text { Cohort } \\
\text { recruitment } \\
\text { acceptable? }\end{array}$ & $\begin{array}{l}\text { Exposure } \\
\text { accurately } \\
\text { measured? }\end{array}$ & $\begin{array}{l}\text { Outcome } \\
\text { accurately } \\
\text { measured? }\end{array}$ & $\begin{array}{l}\text { Important } \\
\text { confounding } \\
\text { factors } \\
\text { identified? }\end{array}$ & $\begin{array}{l}\text { Important } \\
\text { confounding } \\
\text { factors } \\
\text { accounted } \\
\text { for? }\end{array}$ & $\begin{array}{l}\text { Are the } \\
\text { results } \\
\text { precise? }\end{array}$ & $\begin{array}{l}\text { Are the } \\
\text { results } \\
\text { believable? }\end{array}$ & $\begin{array}{l}\text { Do results } \\
\text { fit with } \\
\text { other } \\
\text { available } \\
\text { data? }\end{array}$ & $\begin{array}{l}\text { Overall } \\
\text { quality } \\
\text { score }\end{array}$ \\
\hline $\begin{array}{l}1972, \\
\text { Stuart* }\end{array}$ & [46] & + & + & - & - & + & - & - & - & - & Poor \\
\hline $\begin{array}{l}\text { 1975, } \\
\text { Copeman }\end{array}$ & [44] & - & - & - & - & - & - & $?$ & - & - & Poor \\
\hline 1975, Stuart & [45] & + & + & - & - & - & - & - & - & - & Poor \\
\hline $\begin{array}{l}\text { 1985, } \\
\text { Dawson }\end{array}$ & [55] & + & - & + & + & - & - & $?$ & - & - & Poor \\
\hline $\begin{array}{l}\text { 1994, } \\
\text { Leach }\end{array}$ & [20] & + & + & + & + & - & - & - & + & + & Mod \\
\hline $\begin{array}{l}\text { 1996, } \\
\text { Homøe }\end{array}$ & [34] & + & + & + & + & + & + & + & + & + & Good \\
\hline $\begin{array}{l}\text { 1999, } \\
\text { Parkinson }\end{array}$ & [38] & + & + & + & + & - & - & + & + & + & Mod \\
\hline $\begin{array}{l}\text { 2003, } \\
\text { Couzos* }\end{array}$ & [40] & + & $?$ & + & + & + & + & + & + & + & Good \\
\hline 2003, Stuart & [49] & + & $?$ & + & + & + & - & + & + & + & Mod \\
\hline $\begin{array}{l}\text { 2005, } \\
\text { Gibney }\end{array}$ & [50] & + & + & + & $?$ & - & - & + & + & + & Poor \\
\hline $\begin{array}{l}\text { 2006, } \\
\text { Leach* }\end{array}$ & [51] & + & $?$ & + & + & - & - & - & - & + & Poor \\
\hline $\begin{array}{l}\text { 2007, } \\
\text { Ashhurst- } \\
\text { Smith }\end{array}$ & [37] & + & $?$ & + & + & - & - & $?$ & + & - & Mod \\
\hline $\begin{array}{l}\text { 2008, } \\
\text { Leach* }\end{array}$ & [43] & + & + & + & + & - & - & + & + & + & Mod \\
\hline $\begin{array}{l}\text { 2008, } \\
\text { Leach* }\end{array}$ & [54] & + & + & + & + & - & - & + & + & + & Poor \\
\hline $\begin{array}{l}\text { 2009, } \\
\text { Homøe* }\end{array}$ & [39] & + & + & + & + & - & - & - & - & - & Poor \\
\hline $\begin{array}{l}\text { 2009, } \\
\text { Mackenzie* }\end{array}$ & [52] & + & $?$ & - & + & - & - & + & - & + & Poor \\
\hline $\begin{array}{l}\text { 2010, } \\
\text { Morris * }\end{array}$ & [53] & + & + & + & + & + & + & + & + & + & Good \\
\hline 2011, Binks & [35] & + & $?$ & $?$ & + & - & - & + & + & + & Poor \\
\hline $\begin{array}{l}\text { 2012, } \\
\text { Marsh }\end{array}$ & [56] & + & $?$ & + & + & - & - & + & + & + & Mod \\
\hline 2012 , Sun & [36] & + & + & + & + & + & + & + & + & + & Good \\
\hline $\begin{array}{l}2013, \\
\text { Smith- } \\
\text { Vaughan }\end{array}$ & [48] & + & + & + & + & - & - & + & + & + & Mod \\
\hline $\begin{array}{l}\text { 2013, } \\
\text { Stephen* }\end{array}$ & [42] & + & $?$ & + & + & - & - & + & + & + & Mod \\
\hline $\begin{array}{l}\text { 2015, } \\
\text { Jervis-Bardy }\end{array}$ & [57] & + & $?$ & + & + & + & + & + & + & + & Good \\
\hline $\begin{array}{l}\text { 2015, } \\
\text { Leach* }\end{array}$ & [47] & + & $?$ & + & + & - & - & + & + & + & Mod \\
\hline $\begin{array}{l}\text { 2016, } \\
\text { Leach* }\end{array}$ & [16] & + & $?$ & + & + & + & - & + & + & + & Mod \\
\hline
\end{tabular}

Data based on CASP-based risk of bias assessment. Assessment of bias pertained to the microbiology data and not to clinical data. ?, this variable was unable to be assessed 


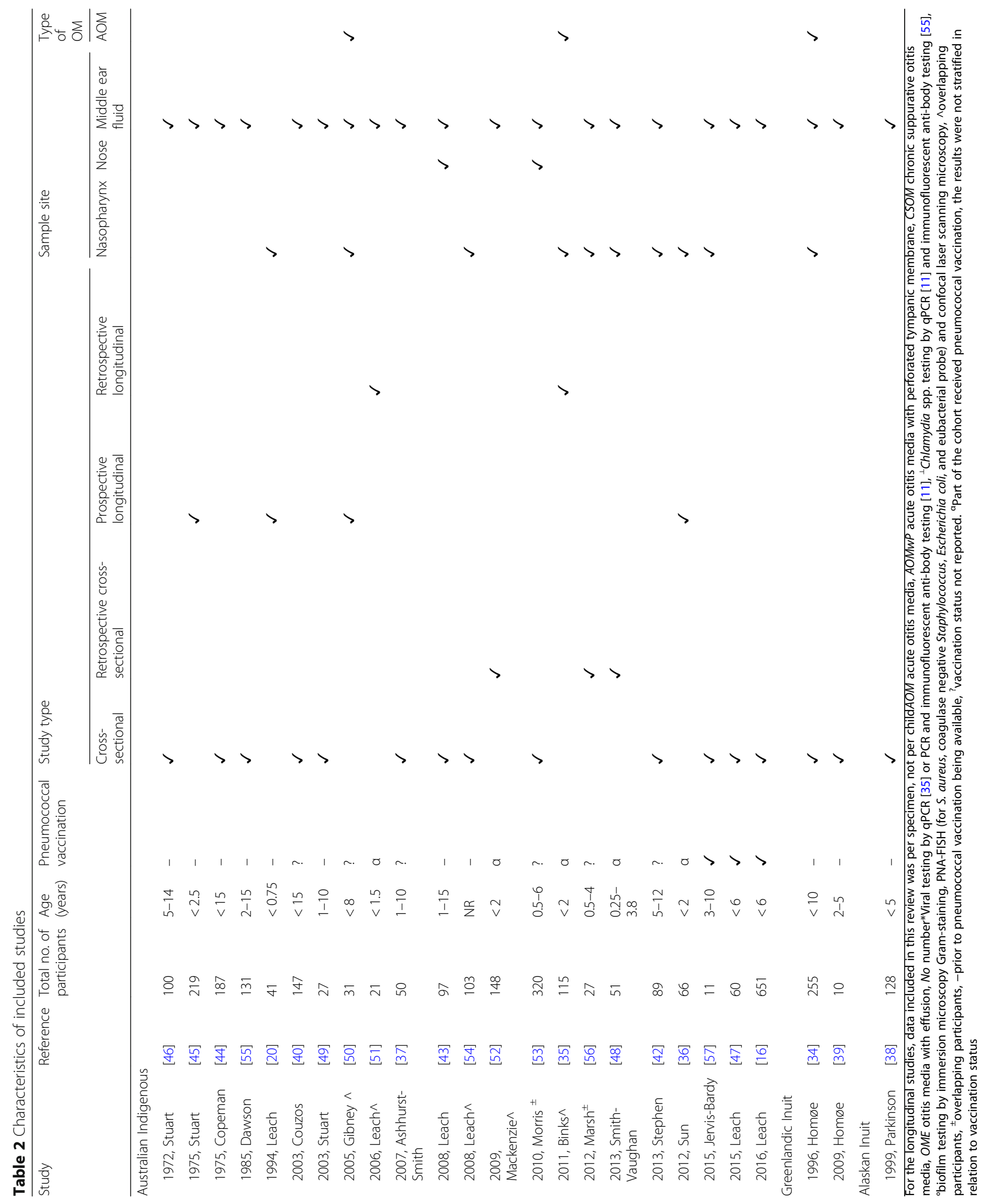




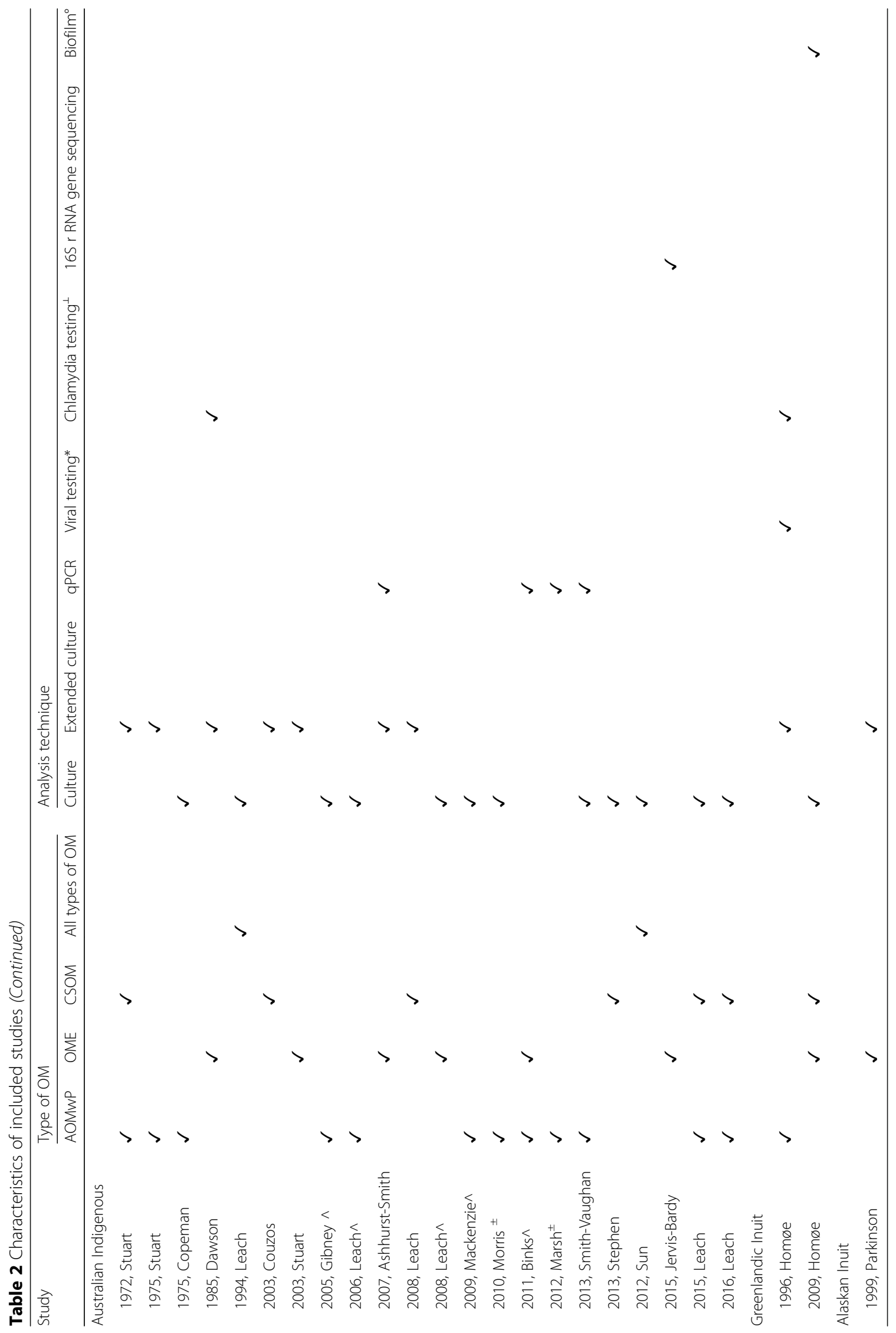




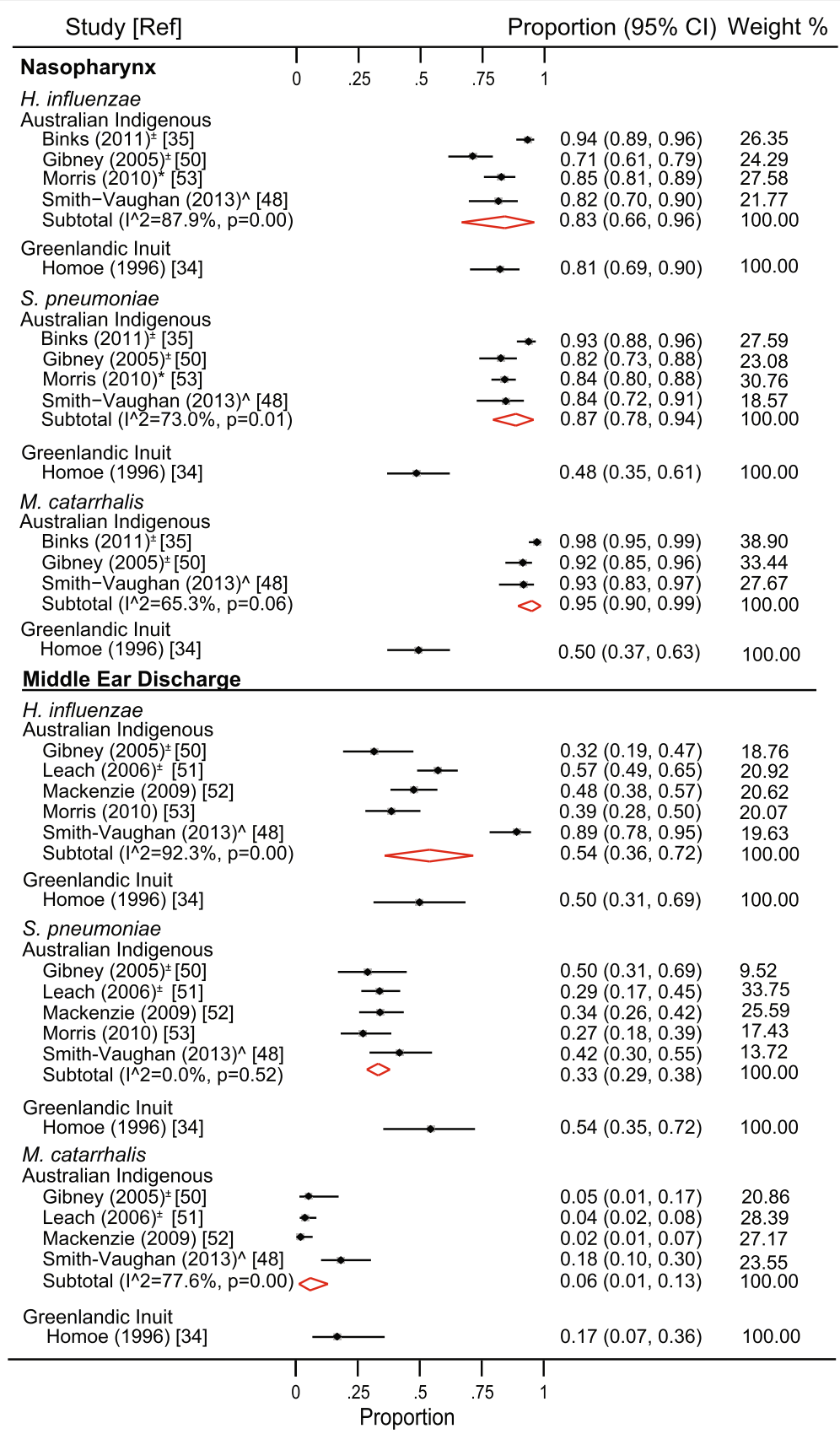

Fig. 2 Forest plot showing bacteriology in relation to acute otitis media. The data are sorted to indicate detection rates for each bacterium in different indigenous populations. Red diamonds indicate subtotal data for different bacteria in each population. Binks et al. 2011 combines AOM and AOMwP. \pm 95\% confidence intervals do not account for multiple swabs from the same child, *nasal swabs, $\wedge$ PCR analysis, Cl confidence interval

but not in the single study of Greenlandic Inuit children (Fig. 4). Yeasts were reported in two Australian Indigenous studies (Additional file 4); one study [40] only detected Candida, Aspergillus, Fusarium, Alternaria, Rhodotorula, Auerobasidium, or Acrinomium in 5\% of MED samples. The other study [43] did not identify or specify the yeasts or fungi detected. No study used molecular methods to explore the URT or middle ear microbiota in CSOM.

\section{Nasopharyngeal carriage as a risk factor for otitis media}

Two prospective cohort studies in Australian Indigenous children explored NP carriage of the three main otopathogens as a risk factor for OM (all types) [20, 36]. A birth cohort study by Leach et al. found that 31/36 (86\%) children with their first episode of OM were colonized with at least one otopathogen [20]. This relationship between NP colonization and OM was stronger when $>1$ otopathogen was detected in the NP (odds 


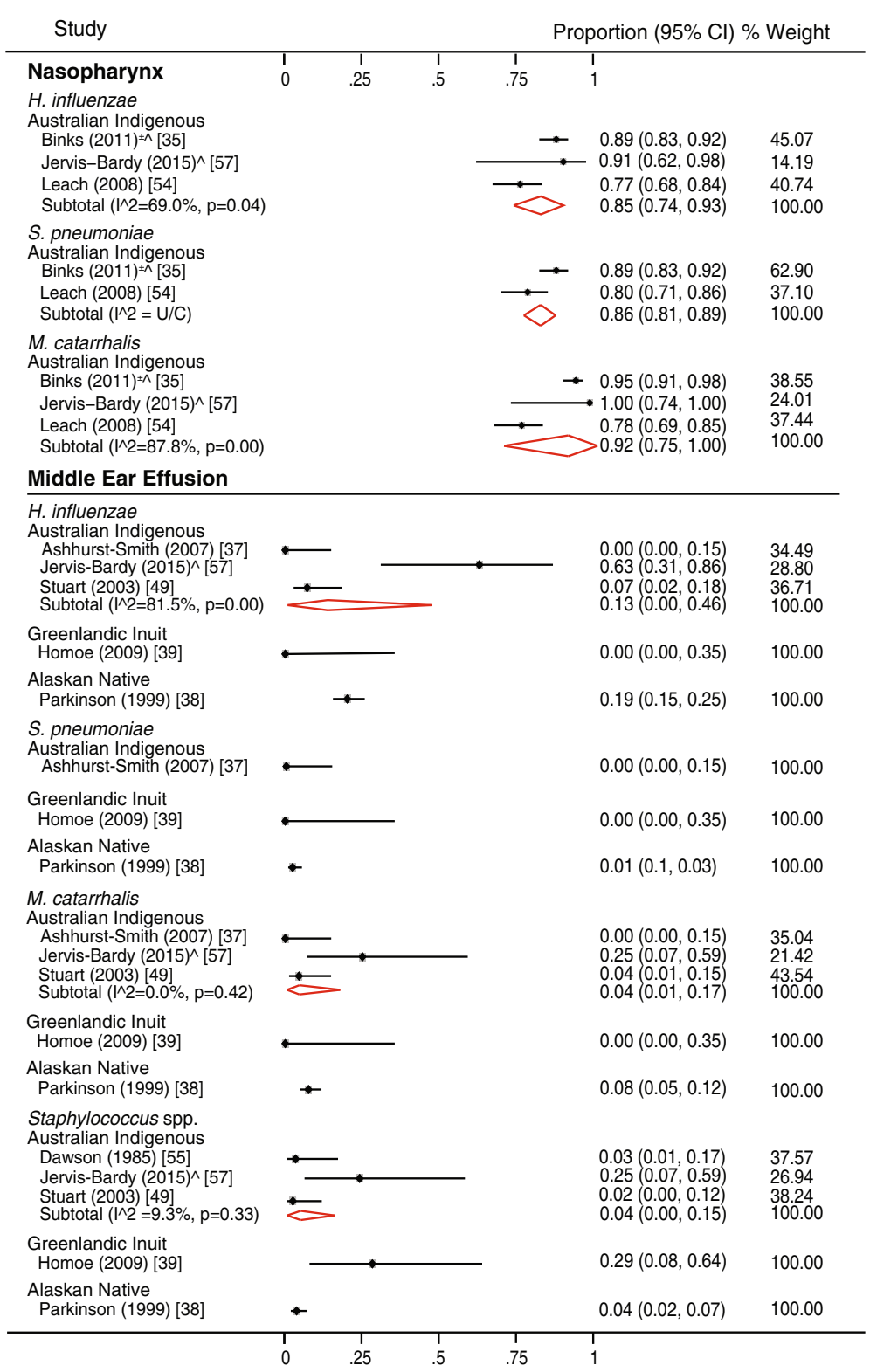

Fig. 3 Forest plot showing bacteriology in relation to otitis media with effusion. The data are sorted to indicate detection rates for each bacterium in different indigenous populations. Red diamonds indicate subtotal data for different bacteria in each population. $\wedge P C R /$ nextgeneration sequencing, U/C unable to calculate

ratio $(\mathrm{OR})=33.6,95 \%$ CI 7.9 to 144 ) [20]. More recently, Sun et al. found that in Australian Indigenous children, early colonization ( 1 to $<3$ months of age) with $H$. influenzae was associated with $\mathrm{OM}$ in the first 2 years of life $(\mathrm{OR}=3.71,95 \%$ CI 1.22 to 11.23$)$ [36]. All children (100\%) who carried $H$. influenzae with either of the other main otopathogens were subsequently diagnosed with OM [36].

\section{Virology}

One Australian [35] and one Greenlandic study [34] tested for viruses in children with OM (Additional file 4).
These studies used different methods for viral detection and, aside from rhinovirus, tested for different viruses (Table 2). In Indigenous Australian children, only adenovirus in the NP was related to AOM (19\%) and AOMwP (20\%) compared to control children (6\%) [35]. There was no relationship between the detection of viruses in the NP and OME [35]. In Greenlandic Inuit children, enteroviruses, rhinoviruses, or "unspecified virus" in the NP were related to AOM, compared to controls [34]. Only one study tested for viruses in the middle ear [34] (Additional file 4). This study detected rhinovirus, enterovirus, or influenzae B in the middle ear discharge of 


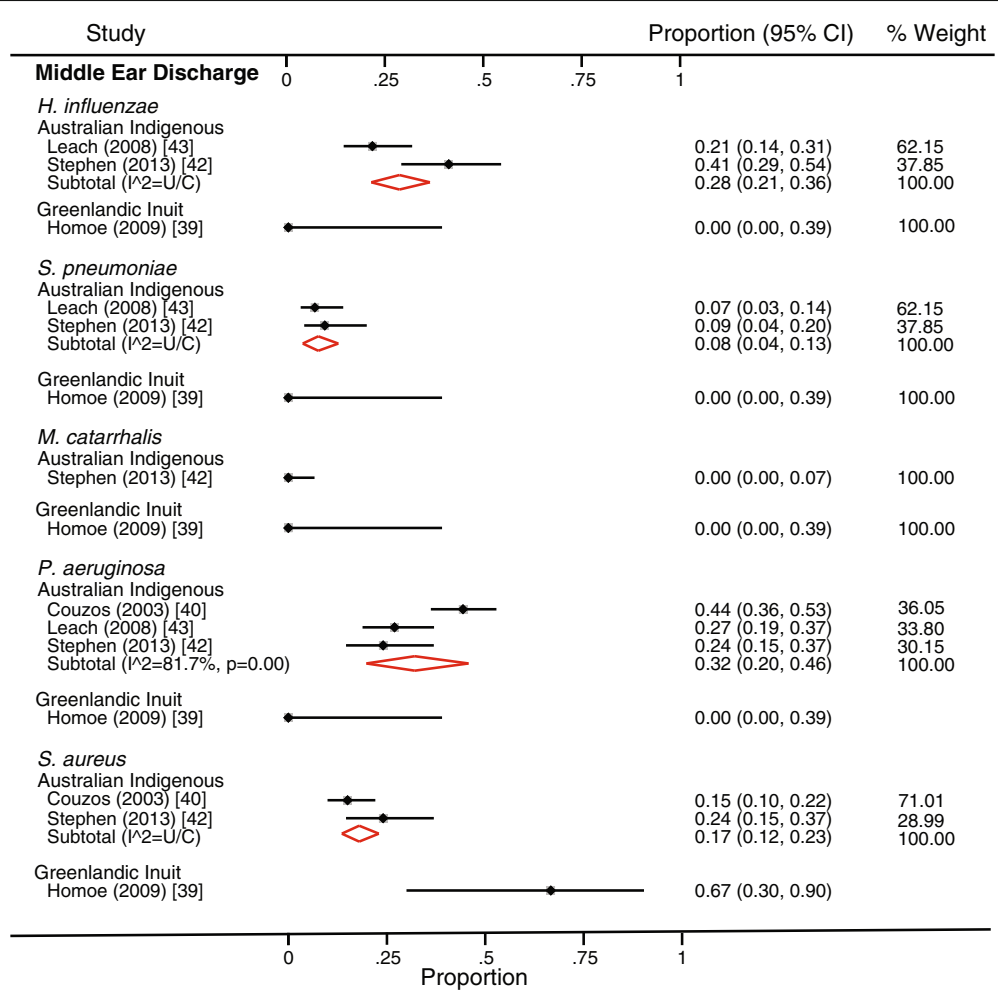

Fig. 4 Forest plot showing bacteriology in relation to chronic suppurative otitis media. The data are sorted to indicate detection rates for each bacterium in different indigenous populations. Red diamonds indicate subtotal data for different bacteria in each population. U/C unable to calculate

eight Greenlandic Inuit children with AOMwP, and two of which concurrently had detection of the virus in the NP [34]. No studies tested for viruses in middle ear specimens in OME or CSOM.

\section{Biofilm}

One Greenlandic study used PNA-FISH to test for biofilm in middle ear specimens from children with CSOM or OME (obtained via sterile aspiration) [39]. Biofilm was detected in 5/6 (83\%) MED samples from children with CSOM using a Eubacterial probe, but not in MEE from seven children with OME [39]. Further testing with species-specific probes found most biofilms (66\%) contained S. aureus. One further sample contained a Stenotrophomonas maltophilia biofilm. For S. aureus and S. maltophilia, there was a $100 \%$ agreement between culture, Gram-staining, and PNA-FISH results [39]. Species-specific probes targeting the main otopathogens were not tested.

\section{Discussion}

This systematic review found the NP of most indigenous children with $\mathrm{OM}$ was colonized with the main otopathogens, particularly those with AOM. In contrast, children with CSOM demonstrate a different middle ear microbial profile compared to children with AOM and OME. Beyond the typical culturable bacteria, data are sparse, limiting our understanding of how the broader microbiota of the URT may contribute to OM pathogenesis and persistence in indigenous populations. Many of the studies included in this systematic review were prior to the development of technologies that could provide a broader analysis of the microbiota such as 16S rRNA next-generation sequencing. Now, such technologies are readily available, there should be a focus on the assessment of the entire OM microbiome across all indigenous populations.

Our analysis highlights the important role of S. pneumoniae and H. influenzae in the pathogenesis of AOM/ $\mathrm{AOMwP}$ and $\mathrm{OME}$ across indigenous populations, consistent with data from non-indigenous populations [58]. These otopathogens were detected at low rates in middle ear samples from children with AOMwP and OME; however, when molecular techniques were employed, detection rates were much higher, particularly for $\mathrm{H}$. influenzae [57], consistent with the increased sensitivity of molecular methods compared to culture [56, 59]. This suggests that current data, which are predominantly culture-based, may underestimate the prevalence of otopathogen colonization in middle ear samples from indigenous children. 
A different pathogen profile was reported from children with CSOM, including $P$. aeruginosa, $S$. aureus, $H$. influenzae, and fungi/yeasts. Commensurate with this result, culture-based literature from non-indigenous children with CSOM often report $P$. aeruginosa and $S$. aureus in MED [60-65]. 16S rRNA gene sequencing of MED from children and adults with CSOM in New Zealand further detected Alloiococcus and Streptococcus [66]. In the CSOM studies included in this review, Alloiococcus would not have been detected, if present, as the specialist culture conditions or PCR required to detect this species were not used. The chronic perforation of the tympanic membrane in CSOM may allow for secondary infection of the middle ear by microbes present in the external auditory canal and could account for the different microbial profile compared to other types of OM. Confirming this, however, is difficult, particularly where a child has had prolonged otorrhoea with ear discharge draining into the canal. Sampling the canal flora of children with intact tympanic membranes as a comparison may provide a solution.

Biofilms have been reported in middle ear specimens from non-indigenous children with CSOM and OME [41, 59, 67-69]; however, this systematic review uncovered very little data pertaining to biofilm in relation to $\mathrm{OM}$ in indigenous children. Considering the high rates of chronic OM, particularly CSOM, this is a noteworthy deficit of the literature.

This systematic review suggests other microbes, beyond the main otopathogens, may be contributing to $\mathrm{OM}$ in indigenous populations; however, there are few data relating to these taxa. Furthermore, detection of these microbes can require specific laboratory techniques. For example, $A$. otitidis detection requires extended culture methods [37] or molecular methods $[56,57]$. Where these methods have been used, A. otitidis was commonly detected [37, 56, 57]; however, it remains controversial whether detection of this species is associated with the middle ear infection or specimen contamination by canal flora [56]. Viruses were seldom investigated in the included studies, and when investigated, different viruses were sought, and detection methods varied. Only one study investigated viruses in middle ear fluid [34]. Viruses are likely to play an important role in OM pathogenesis [70], through numerous potential mechanisms including altering the host immune response [71] and reducing response to antibiotic therapy [72]. Further research is required to determine the contribution of respiratory viruses in $\mathrm{OM}$ pathogenesis.

\section{Limitations of the current literature}

The current literature is limited by methodological heterogeneity, in both the types of laboratory methods used and the OM definitions and diagnoses. There is a bias towards Australian data. The greatest source of methodological heterogeneity was the diversity of methods used to analyze the samples with varying specificities and sensitivities. Inconsistencies in OM definitions and diagnoses were most apparent in the CSOM data, reflecting the absence of internationally accepted definitions [73]. Other OM diagnoses were more consistent, largely because the data was published from a limited number of research groups. International guidelines on OM definitions, diagnosis, and investigation of URT/middle ear microbiota are needed. This will allow for more meaningful comparison of studies from around the world and facilitate future meta-analysis.

The quality of the data included in this review is impacted by the absence of healthy indigenous controls, limited information on participant recruitment, poor consideration of confounding variables, multiple studies where the microbiology is not the primary aim of the study, and population overlap. The absence of healthy indigenous control children may reflect the high burden of disease in many of these populations, for example < $10 \%$ of Australian Indigenous children living in remote areas have healthy ears [7]. To establish a "OM microbiota," comparison with healthy indigenous peers is required. Homøe and colleagues sought to address this issue in their assessment of the nasopharyngeal microbiology of 70 healthy Greenlandic Inuit children using an extended culture-based analysis [74]. They found similar species as children in other parts of the world; however, rates of colonization with the main otopathogens were much higher [74]. Further studies specifically examining for the absence of $\mathrm{OM}$ in healthy indigenous children are required. Similarly, if samples from the external auditory canal are included when analyzing middle ear specimens, we may be able to delineate the role of microbes as contaminate, pathogen, or secondary pathogen (e.g., A. otitidis). There were significant population overlap and small geographical area of recruitment for many studies in Australian Indigenous children. There are documented discordance in $\mathrm{OM}$ burden and prevalence of otopathogen colonization between urban and remote Australian Indigenous children $[75,76]$. Therefore, this limited area of recruitment may impact on generalization of results across Australian Indigenous children.

\section{Future directions}

To further our understanding of OM pathogenesis in indigenous populations and to build upon the current pathogen-based disease model, further research is required to investigate the vast array of microbes that can occupy the URT and how they relate to the known otopathogens to cause disease (Fig. 5). The inclusion of healthy indigenous peers is vital to this goal. Identification of a healthy microbiota in indigenous populations 
- Exploration of entire URT microbiota in indigenous populations. Understanding the entire microbiota can explore the hypothesis of dysbiosis in these populations. This can be achieved using either:

- Metagenomic shot gun sequencing if techniques to remove human DNA advance;

- 16S rRNA gene sequencing with adjunct qPCR; or

- Extended culture with MALDI-TOF and adjunct qPCR - creates microbial resources for further studies, such as bacterial interference.

- Inclusion of healthy indigenous peers in microbiota studies to increase knowledge of the 'healthy' URT microbiota and identification of possible 'protective' microbes

- Inclusion of indigenous participants from diverse geographical, climactic and socioeconomic backgrounds to facilitate generalisation of results.

- Internationally standardised OM diagnostic criteria are needed to enable comparison of data amongst studies from different populations.

- Healthy indigenous control groups

- New therapies to prevent/ reduce colonisation with otopathogens in indigenous populations, including microbiome/ probiotic therapies.

Fig. 5 Recommendations for future research of OM microbiology in indigenous children. OM otitis media, URT upper respiratory tract

may uncover "protective" microbes that can be developed into microbiome/probiotic therapies to protect children from OM. To achieve this outcome, next-generation sequencing can enable deeper exploration of the microbiota without a priori assumptions about the underlying bacterial community, which is required to guide culture-based methods. 16S rRNA gene sequencing, although limited by poor resolution at the species-level, can be augmented by qPCR to provide species-level identification [77]; however, this requires a priori assumptions about the bacteria that should be targeted. Likewise, qPCR for specific viruses is limited by a priori assumptions. These limitations may be overcome with metagenomic shotgun sequencing if the method can be optimized to overcome the technical limitations related to high proportions of human DNA in middle ear specimens. Alternatively, extended culture with matrix-assisted laser desorption ionization-time of flight mass spectrometry (MALDI-TOF MS) identification can be used to provide a broader analysis of the microbiota to the species level [78] and has the benefit of providing material for further studies, such as bacterial interference studies. MALDI-TOF MS is a fast and accurate method of identifying a broad range of bacteria, although is limited by being reliant on a reference database [79]. Furthermore, in the presentation of future microbiological data, stratification of results by age would provide valuable information regarding age-related changes in upper respiratory and middle ear microbiota.

\section{Conclusions}

The URT microbiology in OM is highly complex and dynamic. Through this systematic review, we demonstrated that the three main otopathogens are important in the pathogenesis of AOM across the indigenous populations included and in non-indigenous peers. There is, however, a vast community of microbes present in the URT. How these microbes interact to promote or, perhaps more importantly protect, indigenous children from $\mathrm{OM}$ requires further investigation. A more holistic understanding of the microbial pathogenesis of $\mathrm{OM}$ in indigenous populations enables development of new methods to prevent and treat $\mathrm{OM}$ in these populations.

\section{Additional files}

Additional file 1: Search strategy. (DOCX $13 \mathrm{~kb}$ )

Additional file 2: Summary of OM diagnostic criteria used in studies. (DOCX $12 \mathrm{~kb}$ )

Additional file 3: Summary of three main otopathogens in indigenous children with otitis media. (DOCX $32 \mathrm{~kb}$ )

Additional file 4: Summary of microorganisms reported by studies of URT and/or middle ear specimens using specialist laboratory methods. (DOCX 35 kb)

Additional file 5: Summary of microorganisms identified in the nasopharynx/middle ear using next generation sequencing. (DOCX 14 kb)

\section{Acknowledgements}

Not applicable.

\section{Funding}

Coleman received support from an Avant Doctors in Training Research Scholarship, an NHMRC Postgraduate Research Scholarship (APP1133366), and a Queensland Health Junior Doctor Fellowship.

Marsh is supported by the NHMRC CRE in Respiratory Health of Aboriginal and Torres Strait Islander Children, grant number 1040830.

Cervin is supported by the University of Queensland Faculty of Medicine Strategic Funding and The Garnett Passe \& Rodney Williams Memorial Foundation.

Availability of data and materials

The datasets used and/or analyzed during the current study are available from the corresponding author on reasonable request.

\section{Authors' contributions}

ACol developed the protocol; conducted database searches; reviewed titles, abstracts and papers; extracted and analyzed data; and prepared the manuscript. AW assisted in protocol development; conducted database searches; reviewed titles, abstracts, and papers; and extracted data and prepared the manuscript. SB contributed to the consultation and assistance in protocol development and assisted data analysis and manuscript preparation. RSW contributed to the consultation and assistance in protocol 
development, and consultation and assistance in data analysis and preparation of manuscript. RLM contributed to the consultation and assistance in protocol development and assisted data analysis and manuscript preparation. AC contributed to the consultation and assistance in the development of the protocol and assisted in data analysis and preparation of manuscript. All authors read and approved the final manuscript

\section{Ethics approval and consent to participate} Not applicable.

\section{Consent for publication}

Not applicable.

\section{Competing interests}

The authors declare that they have no competing interests.

\section{Publisher's Note}

Springer Nature remains neutral with regard to jurisdictional claims in published maps and institutional affiliations.

\section{Author details}

${ }^{1}$ Faculty of Medicine, The University of Queensland, Brisbane, Queensland, Australia. ${ }^{2}$ Queensland Pediatric Infectious Disease Laboratory, Centre for Children's Health Research, Children's Health Queensland Hospital, Queensland University of Technology, Child Health Research Centre, The University of Queensland, 62 Graham Street, South Brisbane, Queensland 4101, Australia. ${ }^{3}$ The Deadly Ears Program, Children's Health Queensland Hospital and Health Service, Brisbane, Queensland, Australia. ${ }^{4}$ Menzies Health Institute Queensland, Griffith University, Brisbane, Queensland, Australia. ${ }^{5}$ Menzies School of Health Research, Charles Darwin University, Darwin, Northern Territory, Australia. ${ }^{6}$ Head \& Neck Surgery, Department of Otolaryngology, Royal Brisbane and Women's Hospital, Brisbane, Queensland, Australia.

Received: 26 June 2018 Accepted: 15 October 2018 Published online: 05 November 2018

\section{References}

1. Coticchia JM, Chen M, Sachdeva L, Mutchnick S. New paradigms in the pathogenesis of otitis media in children. Front Pediatr. 2013;1:52.

2. Darwin Otitis Guidelines Group. Recommendations for Clinical Care Guidelines on the Management of Otitis Media in Aboriginal and Torres Strait Islander Populations. Canberra: Department of Health and Ageing; 2010.

3. Burns J, Thomson N. Review of ear health and hearing among Indigenous Australians. 2013. [http://www.healthinfonet.ecu.edu.au/other-healthconditions/ear/reviews/our-review], Accessed 02 Mar 2014.

4. Kong K, Coates HLC. Natural history, definitions, risk factors and burden of otitis media. Med J Aust. 2009;191:S39-43.

5. Daly KA, Hoffman HJ, Jorunn Kvaerner K, Kvestad E, Casselbrant ML, Homoe $P$, Rovers MM. Epidemiology, natural history, and risk factors: panel report from the Ninth International Research Conference on Otitis Media. Int J Pediatr Otorhinolaryngol. 2010;74:231-40.

6. Bhutta MF. Evolution and otitis media: a review, and a model to explain high prevalence in indigenous populations. Hum Biol. 2015;87:92-108.

7. Morris P, Leach AJ, Silberberg P, Mellon G, Wilson C, Hamilton E, Beissbarth J. Otitis media in young Aboriginal children from remote communities in Northern and Central Australia: a cross-sectional survey. BMC Pediatr. 2005;5:27.

8. Jervis-Bardy J, Sanchez L, Carney AS. Otitis media in Indigenous Australian children: review of epidemiology and risk factors. J Laryngol Otol. 2014; 128(Suppl 1):S16-27.

9. Baxter JD. Otitis media in Inuit children in the Eastern Canadian Arctic-an overview -1968 to date. Int J Pediatr Otorhinolaryngol. 1999;49:S165-8.

10. Maynard JE, Fleshman JK, Tschopp CF. Otitis media in Alaskan Eskimo children: prospective evaluation of chemoprophylaxis. JAMA. 1972;219: 597-9.

11. Homøe P, Christensen RB, Bretlau P. Prevalence of otitis media in a survey of 591 unselected Greenlandic children. Int J Pediatr Otorhinolaryngol. 1996; $36: 215-30$.
12. World Health Organisation. Prevention of hearing impairment from chronic otitis media. Geneva: World Health Organisation; 2000.

13. Monasta L, Ronfan L, Marchetti F, Monico M, Vecchi Brumatti L, Bavcar A, Grasso D, Barbiero C, Tamburlini G. Burden of disease caused by otitis media: systematic review and global estimates. PLoS One. 2012;7:e36226.

14. Williams CJ, Jacobs AM. The impact of otitis media on cognitive and educational outcomes. Med J Aust. 2009;191:S69-72.

15. Closing the Gap Clearinghouse (AIHW \& AIFS). Ear disease in Aboriginal and Torres Strait Islander children. Resource sheet no. 35. Produced by the Closing the Gap Clearinghouse. In: Studies AloHaWMAloF. Canberra: Australian Institute of Health and Welfare \& Melbourne: Australian Institute of Family Studies; 2014.

16. Leach AJ, Wigger C, Beissbarth J, Woltring D, Andrews R, Chatfield M, SmithVaughan H, Morris P. General health, otitis media, nasopharyngeal carriage and middle ear microbiology in Northern Territory Aboriginal children vaccinated during consecutive periods of 10-valent or 13-valent pneumococcal conjugate vaccines. Int J Pediatr Otorhinolaryngol. 2016;86: 224-32.

17. Nicholls TR, Leach AJ, Morris PS. The short-term impact of each primary dose of pneumococcal conjugate carriage: a systematic review and metaanalysis of randomised controlled trials. Vaccine. 2016;34:703-13.

18. Leach AJ, Morris PS. Antibiotics for the prevention of acute and chronic suppurative otitis media in children (review). Evid Based Child Health. 2007; 2:697-760.

19. Gunasekera H, Haysom L, Morris P, Craig J. The global burden of childhood otitis media and hearing impairment: a systematic review. Pediatrics. 2008; 121:S107.

20. Leach AJ, Boswell JB, Asche V, Nienhuys TG, Matthews JD. Bacterial colonisation of the nasopharynx predicts very early onset and persistence of otitis media in Australian Aboriginal infants. Pediatr Infect Dis J. 1994;13:983-9.

21. World Health Organisation. Chronic suppurative otitis media: burden of illness and management options. Geneva: World Health Organisation; 2004.

22. Daly KA, Pirie PL, Rhodes KL, Hunter LL, Davey CS. Early otitis media among Minnesota American Indians: the little ears study. Am J Public Health. 2007; 97:317-22.

23. Koch A, Homøe P, Pipper C, Thomas H, Melbye M. Chronic suppurative otitis media in a birth cohort of children in Greenland: population-based study of incidence and risk factors. Pediatr Infect Dis J. 2011;30:25-9.

24. Ursell L, Metcalf J, Wegener Parfrey L, Knight R. Defining the human microbiom. Natr Rev. 2012;70:S38-44.

25. Vergison A. Microbiology of otitis media: a moving target. Vaccine. 2008;26: G5-G10.

26. Biesbroek G, Tsivtsivadze E, Sanders E, Montijn R, Veenhoven R, Keijer BJF, Bogaert $\mathrm{D}$. Early respiratory microbiota composition determines bacterial succession patterns and respiratory health in children. Am J Respir Crit Care Med. 2014;190:1283-92.

27. Sakwinska O, Bastic Schmid V, Berger B, Bruttin A, Keitel K, Legpage M, Moine D, Ngom Bru C, Brüssow H, Gervaix A. Nasopharyngeal microbiota in healthy children and pneumonia patients. J Clin Microbiol. 2014;52:1590-4.

28. Pettigrew M, Laufer A, Gent J, Kong Y, Fennie K, Metlay J. Upper respiratory tract microbial communities, acute otitis media pathogens, and antibiotic use in healthy and sick children. Appl Environ Microbiol. 2012;78:6262-70.

29. Laufer AS, Metlay JP, Gent JF, Fennie KP, Kong Y, Pettigrew MM. Microbial communities of the upper respiratory tract and otitis media in children. MBio. 2011;2:e00245-10.

30. Asia Pacific Forum, United Nations Human Rights Office of the High Commissioner. The United Nations declaration on the rights of indigenous peoples: a manual for the National Rights of Insitutions. Swizerland: Asia Pacific Forum of National Human Rights Institutions and the Office of the United Nations High Commissioner for Human Rights; 2013.

31. de Vet HCW, Dikmans RE, Eekhout I. Specific agreement on dichotomous outcomes can be calculated for more than two raters. J Clin Epidemiol. 2017:83:85-9.

32. Critical Appraisal Skills Program. CASP cohort study checklist. 2017. [http:// www.casp-uk.net/casp-tools-checklists], Accessed 2 May 2017.

33. GRADE Working Group. Grading quality of evidence and strength of recommendations. BMJ. 2004;328:1490.

34. Homøe P, Prag J, Farholt S, Henrichsen J, Hornsleth A, Killian M, Skov Jensen J. High rate of nasopharyngeal carriage of potential pathogens among children in Greenland: results of a clinical survey of middle-ear disease. Clin Infect Dis. 1996;23:1081-90. 
35. Binks MJ, Cheng AC, Smith-Vaughan H, Sloots T, Nissen M, Whiley D, McDonnell J, Leach AJ. Viral-bacterial co-infection in Australian indigenous children with acute otitis media. BMC Infect Dis. 2011;11:161.

36. Sun W, Jacoby P, Riley T, Bowman J, Leach AJ, Coates HLC, Weeks S, Cripps A, Lehmann D. Association between early bacterial carriage and otitis media in Aboriginal and non-Aboriginal children in a semi-arid area of Western Australia: a cohort study. BMC Infect Dis. 2012;12:366.

37. Ashhurst-Smith C, Hall S, Walker P, Stuart J, Hansbro P, Blackwell C. Isolation of Alloiococcus otitidis from Indigenous and non-Indigenous Australian children with chronic otitis media with effusion. FEMS Immunol Med Microbiol. 2007;51:163-70.

38. Parkinson A, Cuthbert M, Bulkow L, Davidson M, Petersen K, Clift S. Bacterial pathogens in chronic otitis media with effusion in Alaska Native children. Alaska Med. 1999;42:27-33

39. Homøe $P$, Bjarnsholt $T$, Wessman $M$, Sørensen $H$, Johansen $H$. Morphological evidence of biofilm formation in Greenlanders with chronic suppurative otitis media. Eur Arch Otorhinolaryngol. 2009;266:1533-8.

40. Couzos S, Lea T, Mueller R, Murray R, Culbong M. Effectiveness of ototopical antibiotics for chronic suppurative otitis media in Aboriginal children: a community-based, multicentre, double-blind controlled trial. Med J Aust. 2003;179:185-90.

41. Jensen $R$, Johansen $H$, Bjarnsholt T, Eickhardt-Sørensen $S$, Homøe P. Recurrent otorrhea in chronic suppurative otitis media: is biofilm the missing link? Eur Arch Otorhinolaryngol. 2017;274:2741-7.

42. Stephen A, Leach AJ, Morris PS. Impact of swimming on chronic suppurative otitis media in Aboriginal children: a randomised controlled trial. Med J Aust. 2013;199:51-5.

43. Leach AJ, Wood Y, Gadil E, Stubbs E, Morris PS. Topical ciprofloxin versus topicalframycetin-gramicidin-dexamethasone in Australian Aboriginal children with recently treated chronic suppurative otitis media. Pediatr Infect Dis J. 2008;27:692-8.

44. Copeman R, Pashen D, Burger G. The health of the Aboriginal children of Cunnamulla, Western Queensland. Med J Aust. 1975;1:8-13.

45. Stuart J. Bacterial flora of the ear, nose, and throat in Aboriginal infants from Brisbane and Cherbourg. Med J Aust. 1975;1:10-44.

46. Stuart J, Quayle C, Lewis A, Harper J. Health, hearing and ear disease in Aboriginal school children. Med J Aust. 1972;22:855-9.

47. Leach AJ, Wigger C, Hare K, Hampton V, Beissbarth J, Andrews R, Chatfield M, Smith-Vaughan H, Morris PS. Reduced middle ear infection with nontypeable Haemophilus influenzae, but not Streptococcus pneumoniae, after transition to 10-valent pneumococcal non-typeable $\mathrm{H}$. influenzae protein D conjugate vaccine. BMC Pediatr. 2015;15:162

48. Smith-Vaughan HC, Binks MJ, Marsh RL, Kaestli M, Ward L, Hare KM, Pizzutto SJ, Thornton RB, Morris PS, Leach AJ. Dominance of Haemophilus influenzae in ear discharge from Indigenous Australian children with acute otitis media with tympanic membrane perforation. BMC Ear Nose Throat Disord. 2013:13:12

49. Stuart J, Butt H, Walker P. The microbiology of glue ear in Australian Aboriginal children. J Paediatr Child Health. 2003;39:665-7.

50. Gibney KB, Morris PS, Carapetis JR, Skull SA, Smith-Vaughan HC, Stubbs E, Leach AJ. The clinical course of acute otitis media in high-risk Australian Aboriginal children: a longitudinal study. BMC Pediatr. 2005;5:16.

51. Leach A, MacKenzie G, Hare KM, Stubbs E, Beissbarth J, Kennedy M, Wilson C, Mellon G, Wigger C, Tippakalipa P, et al. Microbiology of acute otitis media with perforation (AOMwiP) in Aboriginal children living in remote communities - monitoring the impact of 7-valent pneumococcal conjugate vaccine (7vPCV). Int Congr Ser. 2006;1289:89-92.

52. MacKenzie GA, Carapetis JR, Leach AJ, Morris PS. Pneumococcal vaccination and otitis media in Australian Aboriginal infants: comparison of two birth cohorts before and after introduction of vaccination. BMC Pediatr. 2009;9:14

53. Morris PS, Gadil G, McCallum G, Wilson C, Smith-Vaughan H, Torzillo P, Leach AJ. Single-dose azithromycin versus seven days of amoxycillin in the treatment of acute otitis media in Aboriginal children (AATAAC): a double blind, randomised controlled trial. Med J Aust. 2010;192:24-9

54. Leach AJ, Morris PS, Mathews J, Chronic Otitis Media Intervention Trial - One (COMIT1) group. Compared to placebo, long-term antibiotics resolve otitis media with effusion (OME) and prevent acute otitis media with perforation (AOMwiP) in a high-risk population: a randomized controlled trial. BMC Pediatr. 2008:8:23.

55. Dawson VM, Coelen RJ, Murphy S, Graham D, Dyer H, Sunderman J. Microbiology of chronic otitis media with effusion among Australian
Aboriginal children: role of Chlamydia trachomatis. Aust J Exp Biol Med Sci. 1985;63:99-107.

56. Marsh RL, Binks MJ, Beissbarth J, Christensen P, Morris PS, Leach AJ, SmithVaughan $\mathrm{H}$. Quantitative PCR of ear discharge from Indigenous Australian children with acute otitis media with perforation supports a role for Alloiococcus otitidis as a secondary pathogen. BMC Ear Nose Throat Disord. 2012;12:11.

57. Jervis-Bardy J, Rogers GB, Morris PS, Smith-Vaughan HC, Nosworthy E, Leong LEX, Smith RJ, Weyrich LS, De Haan J, Carney AS, et al. The microbiome of otitis media with effusion in Indigenous Australian children. Int J Pediatr Otorhinolaryngol. 2015;79:1548-55

58. Ngo CC, Massa HM, Thornton RB, Cripps AW. Predominant bacteria detected from the middle ear fluid of children experiencing otitis media: a systematic review. PLoS One. 2016;11:e0150949.

59. Hall-Stoodley L, Gieseke A, Nistico L, Nguyen D, Hayes J, Forbes M, Greenberg DP, Dice B, Burrows A, Wackym A, et al. Direct detection of bacterial biofilms on the middle-ear mucosa of children with chronic otitis media. JAMA. 2006;296:202-11.

60. Prakash R, Juyal D, Negi V, Pal S, Adekhadi S, Sharma M, Sharma N. Microbiology of chronic suppurative otitis media in a tertiary care setup of Uttarakhand state, India. N Am J Med Sci. 2013;5:282-7.

61. Kumar R, Agarwal R, Gupta S. A microbiological study of chronic suppurative otitis media. Int J Recent Sci Res. 2015;6:5487-90.

62. Yeo S, Park D, Hong S, Cha C, Kim M. Bacteriology of chronic suppurative otitis media--a multicenter study. Acta Otolaryncol. 2007;127:1062-7.

63. Dayasena R, Dayasiri M, Jayasuriya C, Perera D. Aetiological agents in chronic suppurative otitis media in Sri Lanka. Australas Med J. 2011;4:101-4.

64. Aflobi O, Salaudeen A, Ologe F, Nsabuisi C. Nwawolo: pattern of bacterial isolates in the middle ear discharge of patients with chronic suppurative otitis media in a tertiary hospital in North central Nigeria. Afr Health Sci. 2012;12:362-7.

65. Mittal R, Lisi C, Gerring R, Mittal J, Mattal J, Mathee K, Narasimhan G, Azad R, Grati M, Eshranghi A, et al. Current concepts in the pathogenesis and treatment of chronic suppurative otitis media. J Med Microbiol. 2015;64:1103-16.

66. Neef M, Biswas K, Hoggard M, Taylor M, Douglas R. Molecular microbiological profile of chronic suppurative otitis media. J Clin Microbiol. 2016:54:2538-46.

67. Kaya E, Dag I, Incesulu A, Gurbuz MK, Acar M, Birdane L. Investigation of the presence of biofilms in chronic suppurative otitis media, nonsuppurative otitis media, and chronic otitis media with cholesteatoma by scanning electron microscopy. Sci World J. 2013;2013:638715.

68. Lee MR, Pawlowski KS, Luong A, Furze AD, Sargent Roland P. Biofilm presence in humans with chronic suppurative otitis media. Otolaryngol Head Neck Surg. 2009;141:567-71.

69. Thornton RB, Rigby PJ, Wiertsema SP, Filion P, Langlands J, Coates H, Vijayasekaran S, Keil AD, Richmond PC. Multi-species bacterial biofilm and intracellular infection in otitis media. BMC Pediatr. 2011;11:94.

70. Heikkinen T, Chonmaitree T. Importance of respiratory viruses in acute otitis media. Clin Microbiol Rev. 2003;16:230-41.

71. Abramson J, Giebink G, Quie P. Influenza A virus-induced polymorphonuclear leukocyte dysfunction in the pathogenesis of experimental pneumococcal otitis media. Infect Immun. 1982;36:289-96.

72. Chonmaitree $T$, Owen $M$, Howie V. Respiratory viruses interfere with bacteriologic response to antibiotic in children with acute otitis media. J Infect Dis. 1990:162:546-9.

73. Homøe P, Kvarner K, Damoiseaux RAMJ, van Dongen TMA, Gunasekera H, Jensen R, Morris P, Weinreich HM. Panel 1: epidemiology and diagnosis. Otolaryngol Head Neck Surg. 2017;156:S1-S21.

74. Homøe P, Prag J, Olsen C, Farholt S. Nasopharyngeal bacteria found on blood agar plates from healthy children in Greenland. Int J Circumpolar Health. 1998;57:32-9.

75. Gunasekera H, Morris PS, Daniels J, Couzos S, Craig JC. Otitis media in Aboriginal children: the discordance between burden of illness and access to services in rural/remote and urban Australia. J Paediatr Child Health. 2009;45:425-30.

76. O'Grady K, Hall K, Sloots T, Anderson J, Chang A. Upper airway viruses and bacteria in urban Aboriginal and Torres Strait Islander children in Brisbane: a cross-sectional study. BMC Infect Dis. 2017;17:245.

77. Sillanpää S, Kramna L, Oikarinen S, Sipilä M, Rautiainen M, Aittoniemi J, Laranne J, Hyöty H, Cinek O. Next-generation sequencing combined with specific PCR assays to determine the bacterial 165 rRNA gene profiles of 
middle ear fluid collected from children with acute otitis media. mSphere. 2017;2:e00006-17.

78. Sung JY, Hwang Y, Shin HM, Park MS, Lee SH, Yong D, Lee K. Untility of cenventional culture and MALDI-TOF MS for indentification of microbial communities in brochoalveolar lavage fluid in comparison with GS junior next generation sequencing system. Ann Lab Med. 2018;38:110-8.

79. Singal N, Kumar M, Kanaujina P, Virdi J. MALDI-TOF mass spectrometry: an emerging technology for microbial identification and diagnosis. Front Microbiol. 2015;6:791.

- fast, convenient online submission

- thorough peer review by experienced researchers in your field

- rapid publication on acceptance

- support for research data, including large and complex data types

- gold Open Access which fosters wider collaboration and increased citations

- maximum visibility for your research: over $100 \mathrm{M}$ website views per year

At BMC, research is always in progress.

Learn more biomedcentral.com/submissions 